\title{
Non-steroidal anti-inflammatory agents for cystoid macular oedema following cataract surgery: a systematic review
}

\section{S Sivaprasad, C Bunce, R Wormald}

Aim: To examine the effectiveness of non-steroidal antiinflammatory drugs (NSAIDs) in the treatment of cystoid macular oedema (CMO) following cataract surgery.

Methods: Systematic literature review of randomised controlled trials (RCTs) that evaluated the effects of NSAIDs in the treatment of $\mathrm{CMO}$ following cataract surgery was done according to the Cochrane Collaboration methodology.

Results: Seven trials involving a total of 266 participants were included. Four trials studied the effects of NSAIDs in chronic $\mathrm{CMO}$ while the other three trials examined the effect of NSAIDs in acute CMO. Little evidence of effectiveness was found for oral indomethacin and topical fenoprofen for chronic CMO in two small trials. Treatment with topical $0.5 \%$ ketorolac for chronic CMO was found to be effective in two trials. Three trials examined the effect of topical NSAIDs on acute $\mathrm{CMO}$. The comparisons among these studies were of a NSAID to placebo, prednisolone or another NSAID. Because of considerable heterogeneity between these study designs, their results were not combined in a meta-analysis.

Conclusion: A positive effect of topical NSAID $10.5 \%$ ketorolac tromethamine ophthalmic solution) on chronic $\mathrm{CMO}$ was noted. However, there is not enough evidence to show the effectiveness of NSAIDs in acute CMO following cataract surgery.

$\mathrm{D}$ espite advances in cataract surgery, cystoid macular oedema (CMO) is still recognised as one of the most common causes of poor visual outcome following cataract surgery.

The exact cause of CMO remains unclear. Most investigators agree that increased prostaglandin synthesis secondary to inflammation is a major aetiological factor for CMO. Topical non-steroidal anti-inflammatory agents (NSAIDs) have been used since the 1970s both preoperatively and postoperatively to prevent and treat CMO following cataract surgery.

A systematic review on the medical prophylaxis and treatment of CMO after cataract surgery was published in 1998. ${ }^{2}$ However, no conclusion could be safely drawn since the authors commented that many of the trials were of poor quality and may additionally be regarded as too heterogeneous to include in one meta-analysis. Therefore, uncertainty of the effectiveness of NSAIDs in the treatment of CMO persists

The aim of this review based on Cochrane methodology is to examine the effectiveness of NSAIDs in the treatment of CMO following cataract surgery. The role of NSAIDs in the prophylaxis of CMO is not included.

\section{MATERIALS AND METHODS}

Study inclusion criteria and search strategy

This review included randomised controlled trials in which NSAIDs in any form or dosage were compared to placebo, no treatment, or to another modality with the aim of treating
CMO following cataract surgery in eyes that were otherwise healthy.

CMO was classified into two groups: acute CMO defined as therapeutic intervention within 4 months of onset of CMO and chronic CMO defined as persistence of clinical CMO 4 months after cataract surgery and treatment commenced after 4 months.

Trials were identified from the Cochrane Central Register of Controlled Trials, CENTRAL (which contains the Cochrane Eyes and Vision Group Trials Register) on The Cochrane Library, Medline, Embase and LILACS (Latin American and Caribbean Literature on Health Sciences) using a search strategy that we have reported elsewhere. ${ }^{3}$ Reference lists of all identified trials and previous reviews were searched for additional trials. Key authors were identified and asked to identify additional published or unpublished trials. Additionally, manufacturers of non-steroidal anti-inflammatory drugs (Allergan, Inc (NYSE: AGN) and Novartis, Inc (Basle, Switzerland)) were contacted in order to retrieve information on relevant published or unpublished trials. We searched conference abstracts (sessions related to cataract) in ARVO 1975 to 2004 for mention of trials. Manual searches of journals were not done specifically for this review. There were no language or date restrictions in the electronic searches for trials. The searches were last updated in October 2004.

\section{Selection of trials}

Two reviewers independently scanned the titles, abstracts, and keywords of every record retrieved in the searches. Full articles were obtained of any trial that seemed to fit in the inclusion criteria. Four aspects of the trials were assessed. They included allocation concealment, masking of participants and researchers, detection bias, and attrition bias-that is, whether the analysis was "intention to treat."

\section{Types of outcome measures}

The primary outcome measures were:

- An improvement of two or more lines in Snellen visual acuity or equivalent at end of treatment.

- Persistence of improvement of vision 1 month after discontinuation of treatment.

The secondary outcome measures were:

- Proportion of participants with improvement in leakage on fundus fluorescein angiography (FFA).

- Proportion of participants with improved contrast sensitivity.

- Quality of life.

Review Manager Software (version 4.2) was used to analyse the data.

Abbreviations: CMO, cystoid macular oedema; NSAIDs, non-steroidal anti-inflammatory agents; RCT, randomised controlled trial 
Table 1 Details of included studies

\begin{tabular}{|c|c|c|c|c|}
\hline Study & Type of study & Participants & Interventions & Cataract surgery \\
\hline Burnett $^{9}$ & $\begin{array}{l}\text { Randomised double } \\
\text { masked. }\end{array}$ & Number randomised: 14 & $\begin{array}{l}\text { Topical } 1 \% \text { fenoprofen sodium } v \text { placebo four } \\
\text { times daily for } 8 \text { weeks. }\end{array}$ & $\begin{array}{l}\text { Aphakic eyes with chronic } \\
\text { CMO. }\end{array}$ \\
\hline Flach $^{10}$ & $\begin{array}{l}\text { Randomised double } \\
\text { masked. }\end{array}$ & $\begin{array}{l}\text { Number randomised: } 30 \\
\text { Outcome on } 26\end{array}$ & $\begin{array}{l}\text { Topical } 0.5 \% \text { ketorolac tromethamine } v \text { placebo } \\
\text { four times daily for } 8 \text { weeks. }\end{array}$ & $\begin{array}{l}\text { Aphakic and pseudophakic } \\
\text { eyes with chronic } \mathrm{CMO} \text {. }\end{array}$ \\
\hline Flach $^{8}$ & $\begin{array}{l}\text { Randomised double } \\
\text { masked, multicentre } \\
\text { study. }\end{array}$ & $\begin{array}{l}\text { Number randomised: } 120 \\
\text { ( } 61 \text { to active treatment, } 59 \text { to } \\
\text { placebo). }\end{array}$ & $\begin{array}{l}\text { Topical } 0.5 \% \text { ketorolac tromethamine } v \text { placebo } \\
\text { four times daily for } 12 \text { weeks. }\end{array}$ & $\begin{array}{l}\text { Aphakic and pseudophakic } \\
\text { eyes with chronic } \mathrm{CMO} \text {. }\end{array}$ \\
\hline Yanuzzi $^{11}$ & $\begin{array}{l}\text { Randomised double } \\
\text { masked. }\end{array}$ & Number randomised: 20 & $\begin{array}{l}\text { Oral indomethacin } 25 \mathrm{mg} v \text { placebo three times a } \\
\text { day for } 6 \text { weeks. }\end{array}$ & Aphakic chronic CMO. \\
\hline Flach $^{5}$ & $\begin{array}{l}\text { Randomised double } \\
\text { masked, crossover } \\
\text { study. }\end{array}$ & $\begin{array}{l}\text { Number randomised: } 24,22 \\
\text { followed up to } 2 \text { months. }\end{array}$ & $\begin{array}{l}\text { Topical } 0.5 \% \text { ketorolac tromethamine } v \text { placebo four } \\
\text { times daily for } 4 \text { weeks. }\end{array}$ & $\begin{array}{l}\text { Aphakic and pseudophakic } \\
\text { eyes with acute CMO. }\end{array}$ \\
\hline Heier $^{6}$ & $\begin{array}{l}\text { Randomised double } \\
\text { masked. }\end{array}$ & $\begin{array}{l}\text { Number randomised: } 28,26 \\
\text { completed the study. }\end{array}$ & $\begin{array}{l}\text { One drop topical } 0.5 \% \text { ketorolac tromethamine and } \\
\text { artificial tears } v \text { prednisolone acetate and one drop } \\
\text { topical } 0.5 \% \text { ketorolac tromethamine and artificial } \\
\text { tears } v \text { prednisolone acetate and combination four } \\
\text { times daily for a maximum of } 12 \text { weeks. Treatment } \\
\text { tapered earlier if } C M O \text { resolved. }\end{array}$ & $\begin{array}{l}\text { Aphakic and pseudophakic } \\
\text { eyes with acute } \mathrm{CMO} \text {. }\end{array}$ \\
\hline $\mathrm{Rho}^{7}$ & $\begin{array}{l}\text { Randomised un- } \\
\text { masked. }\end{array}$ & Number randomised: 34 & $\begin{array}{l}\text { Topical } 0.5 \% \text { ketorolac tromethamine } v \text { topical } 0.1 \% \\
\text { diclofenac sodium one drop four times daily. }\end{array}$ & $\begin{array}{l}\text { Pseudophakic eyes with } \\
\text { acute } \mathrm{CMO} \text {. }\end{array}$ \\
\hline
\end{tabular}

\section{RESULTS}

\section{Description of studies}

The electronic searches found a total of 382 reports of studies. We obtained the full copy of 17 reports of trials that appeared to meet the inclusion criteria. We excluded 10 of these. In particular, all trials that used NSAIDs for prophylaxis of CMO were excluded. We included seven trials. ${ }^{5-11}$ A summary of the included studies is given in table 1 .

\section{Acute CMO}

Three trials studied acute CMO, defined as treatment of CMO within 4 months of cataract surgery. ${ }^{5-7}$

In the trial by Heier et al, outcome measures used included proportion of patients with an improvement of two or more lines in Snellen visual acuity and decreased angiographic leakage at the end of 1 month. ${ }^{6}$ They also noted the proportion of participants with an improvement of contrast sensitivity 1 month after discontinuation of medications. This trial showed that the combination of ketorolac and prednisolone was more effective in the management of acute CMO compared to either ketorolac or prednisolone alone. ${ }^{6}$

In the study by Rho et al, the mean time taken for a two line improvement in Snellen visual acuity and resolution of CMO was compared and found to be equally effective for the $0.1 \%$ diclofenac sodium and $0.5 \%$ ketorolac tromethamine groups. $^{7}$

The crossover study by Flach showed little evidence of any difference between $0.5 \%$ ketorolac and placebo in achieving a two line improvement in Snellen visual acuity at the end of the crossover period. The study did not report angiographic response to treatment. Quality of life was not assessed although it is mentioned that the visual acuity improved in 20 of the total 22 participants in the trial 7 years after completion of the trial. ${ }^{5}$

\section{Chronic CMO}

Figure 1 shows the improvement of visual acuity at the end of treatment with the various NSAIDs compared to placebo in the four studies on chornic CMO. The effects of these NSAIDs on visual acuity were also noted 1 month after cessation of treatment in three studies (fig 2).

None of the trials assessed quality of life.

\section{Adverse effects}

In all the trials, only one case of ocular allergy has been reported and the patient discontinued the treatment. No other mention of adverse effects was found.

\section{DISCUSSION}

\section{Acute CMO}

All three randomised controlled trials assessing the effect of NSAIDs in the treatment of acute CMO were small and insufficiently powered..$^{5-7}$ Spontaneous resolution and drug effect in acute CMO are hard to distinguish in these studies. Outcomes at 7 years suggest the natural history of CMO is spontaneous resolution. ${ }^{5}$

The three trials showed different effects of NSAIDs in the treatment of acute CMO.

This difference in effect can be explained by the following facts:

Review: Non-steroidal anti-inflammatory agents for treating cystoid macular oedema following cataract surgery

Comparison: NSAID versus placebo in chronic CMO

Outcome: Visual acuity improvement at end of treatment

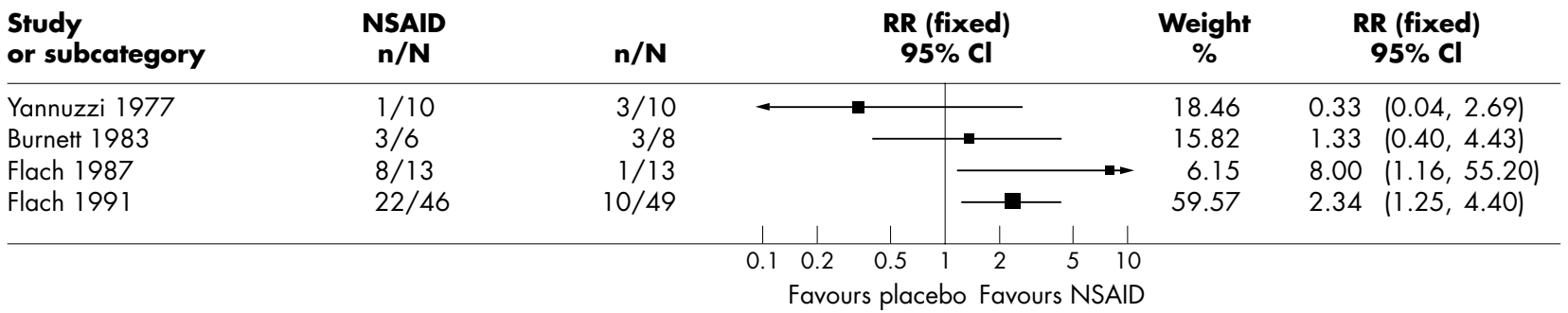

Figure 1 Improvement of vision at end of treatment. 
Review: Non-steroidal anti-inflammatory agents for treating cystoid macular oedema following cataract surgery Comparison: NSAID versus placebo in chronic CMO

Outcome: Visual acuity improvement 1 month post treatment

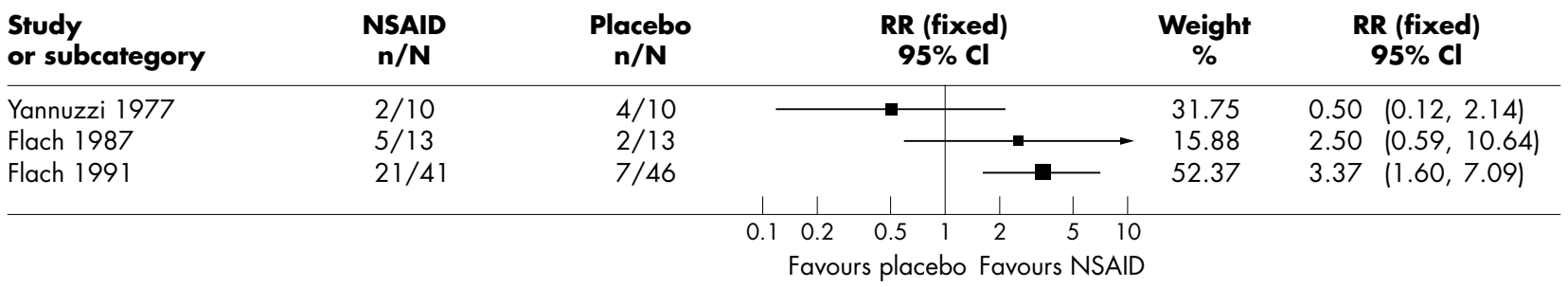

Figure 2 Improvement of vision 1 month after treatment.

- Though all three trials used $0.5 \%$ topical ketorolac tromethamine as the NSAID, the NSAID was compared with different interventions.

- The duration of treatment varied in all three trials.

- The duration of CMO was less than 45 days in one study, ${ }^{7}$ 45-49 days in the study by Heier et $a l^{6}$ and 60-90 days in Flach's trial. ${ }^{5}$

- The cataract surgery was different in the three trials. ${ }^{5-7}$ The participants in trials by Heier et al and Rho et al underwent uncomplicated phacoemulsification and intraocular lens implantation while Flach included extracapsular cataract surgery and intraocular lens implantation including complicated cases.

We could not conduct a meta-analysis because of the heterogeneity in study design.

\section{Chronic CMO}

The four trials on NSAIDs for chronic CMO showed a broad range of therapeutic effects. ${ }^{8-11}$ One trial showed a negative but not statistically significant effect of oral NSAIDs in chronic CMO, which raises doubts about the role of oral NSAIDs in ocular disease. ${ }^{11}$ Of the trials that used topical NSAID, one study found a positive but not significant effect ${ }^{9}$ and the other two studies found a statistically significant benefit. ${ }^{8}{ }^{10}$ However, the two older studies with negative results included only aphakic eyes (intracapsular cataract surgery),,$^{91}$ while the newer studies included both aphakic and pseudophakic eyes (intracapsular and extracapsular cataract surgery with intraocular lens implantation). ${ }^{8}{ }^{10}$ The different surgical techniques and associated inflammation and the light transmission characteristics of the various intraocular lenses may be important variables that affected the results.

The variability in results can also be explained by the fact that different NSAIDs were used in the various trials. Oral indomethacin was found to be ineffective in the treatment of clinical chronic CMO. ${ }^{11}$ Topical fenoprofen was not shown to be effective. ${ }^{9}$ The only NSAID found to be effective is topical $0.5 \%$ ketorolac tromethamine. ${ }^{8} 10$

Another factor is the small sample size in three of the four studies. ${ }^{9-11}$ These sample sizes are too small to allow subgroup analysis of the duration of decreased visual acuity and the resultant structural changes at the macula that can influence the initial vision, response to treatment, and final outcome.

Comparison of duration of treatment in the two trials that showed some benefit of topical ketorolac for chronic CMO also showed different time frames (2 months and 3 months). ${ }^{811}$ Three months' duration showed better therapeutic response but the study samples were different (30 versus 120 participants).

All studies used angiographic evidence as one of the criteria to confirm clinically significant CMO. However, since improvement in vision does not correlate with angiographic changes, angiography is of doubtful value as an outcome in future studies. ${ }^{910}$

\section{CONCLUSION}

The evidence of the effectiveness of NSAIDs for acute or chronic CMO is insufficient to clearly inform practice. The therapeutic effect of NSAIDs on CMO needs to be assessed by larger trials with longer follow up.

\section{ACKNOWLEDGEMENTS}

We would like to thank the Cochrane Eyes and Vision Group for their help with preparing the electronic searches and peer reviewing this manuscript. We acknowledge Adriaan van Sorge for registering the title for Cochrane review and and Nishal Patel for help with data collection.

\section{Authors' affiliations \\ S Sivaprasad, C Bunce, R Wormald, Moorfields Eye Hospital, London,} UK

Financial interest: none

Comepting interests: none declared

Correspondence to: Mr Richard Wormald, Moorfields Eye Hospital, 162 City Road, London ECIV 2PD, UK; r.wormald@ucl.ac.uk

Accepted for publication 7 July 2005

\section{REFERENCES}

1 Drolsum L, Haaskjold E. Causes of decreased visual acuity after cataract extraction. J Cataract Refract Surg 1995;21:59-63.

2 Rossetti L, Chaudhuri J, Dickersin K. Medical prophylaxis and treatment of cystoid macular edema after cataract surgery. The results of a meta-analysis. Ophthalmology 1998;105:397-405.

3 Sivaprasad S, Bunce C, Patel N. Non-steroidal anti-inflammatory agents for treating cystoid macular oedema following cataract surgery. The Cochrane Database of Systematic Reviews 2004, Issue 3. Art. No.: CD 004239. DOI:10.1002/14651858.CD004239.pub2.

4 Alderson P, Green S, Higgins JPT, eds. Cochrane reviewers' handbook 4.2.2 In: The Cochrane Library, Issue 1, 2004. Chichester: John Wiley \& Sons, Ltd (updated March 2004).

5 Flach AJ. The incidence, pathogenesis and treatment of cystoid macular edema following cataract surgery. Trans Am Ophthalmol Soc 1998:96:557-634.

6 Heier JS, Topping TM, Chern S, et al. Ketorolac versus prednisolone versus combination therapy in the treatment of acute pseudophakic cystoid macular edema. Ophthalmology 2000;107:2034-9.

7 Rho DS. Treatment of acute pseudophakic cystoid macular edema: diclofenac versus ketorolac. J Cataract Refract Surg 2003;29:2378-84

8 Flach AJ, Jampol LM, Weinberg D, et al. Improvement in visual acuity in chronic aphakic and pseudophakic cystoid macular edema after treatment with topical 0.5\% ketorolac tromethamine. Am J Ophthalmol $1991 ; 112: 514-19$.

9 Burnett J, Tessler H, Isenberg S, et al. Double-masked trial of fenoprofen sodium: treatment of chronic aphakic cystoid macular edema. Ophthalmic Surg 1983;14:150-2.

10 Flach AJ, Dolan BJ, Irvine AR. Effectiveness of ketorolac tromethamine $0.5 \%$ ophthalmic solution for chronic aphakic and pseudophakic cystoid macular edema. Am J Ophthalmol 1987; 103:479-86.

11 Yannuzzi LA, Klein RM, Wallyn RH, et al. Ineffectiveness of indomethacin in the treatment of chronic cystoid macular edema. Am J Ophthalmol 1977;84:517-19. 